\title{
Self-Conceptions and Evolution: A Critical Comment on Philip Kitcher's The Ethical Project
}

Ivo Wallimann-Helmer

\begin{abstract}
Summary: This paper provides a critical comment on Philip Kitcher's as yet unpublished book The Ethical Project. In the first part it explains why Kitcher's position is naturalist as well as pragmatist. In the second part it is argued that the role ethics plays in human history is richer than Kitcher conceives it: Building on his view, this paper suggests that ethics not only provides a mechanism to diminish the risk of social conflict and social instability, but it also enables the emergence of self-conceptions. This reveals according to what processes certain particular changes occurred in the evolution of ethics.
\end{abstract}

This is a critical comment on Kitcher's "The Ethical Project", which will be published in 2011. ${ }^{1}$ Though not yet published, this book (its manuscript) has already prompted tremendous discussion and will doubtless inspire debate in moral philosophy. As I share much of Kitcher's view on the evolution of ethics, this comment might look like an advertisement for a new book. Though I share much of Kitcher's view I would like to suggest, that he not tells the full story. However, I hope my criticism will be understood as a measure of the strength of Kitcher's story on the evolution of ethics. A story that invites a range of further research that, like my own proposal here, would hope to both inform as well as be informed by Kitcher's insights.

In what follows, I first introduce the main idea which grounds

1 This is the reason why references to the book are only made with regard to paragraphs and not single pages. 
the view of the ethical project I ascribe to Kitcher (1): In human history, ethics plays the role of a mechanism to diminish social conflict and the risk of social instability. Then, I argue for a perspective on the ethical project which conceives of it as an evolution of self-conceptions (2). In conclusion I will argue that both perspectives might inform each other vice versa (3).

\section{Pragmatic naturalism}

Kitcher's book divides into three parts. Part I provides an analytic history of the evolution of ethics centred on the capacity for psychological altruism. The capacity for psychological altruism is a necessary condition for human beings to be able to live together in groups of mixed age and sex. Part II develops a theory of ethical truth and progress. It argues that evolution in ethics is to be understood not only as the accidental occurrence of changes, but as a progressive venture which makes manifest vague, core truths in ethics. Part III provides a normative theory which shows how we, now, should proceed with ethical questions. This theory is defended on the basis of the initial role ethics played in human history. To show why, I believe, Kitcher sees the role of ethics as a mechanism for diminishing social conflict and the risk of social instability, I will focus on the central conceptions defended in Parts I and II. These conceptions and their relation can be nicely explained with regard to the name Kitcher gives his theory: Pragmatic Naturalism $(\S 1)$.

Kitcher's position is naturalist because the fundamental basis for the evolution of ethics lies in two facts: First, the ethical project started in human history when our ancestors acquired the ability to live together, i.e.; a capacity for psychological altruism. Secondly, although humans achieved the capacity for psychological altruism, they still followed selfish goals. Consequently, this made it necessary to establish social rules and mechanisms of control which enabled these failures to be corrected.

Given these two facts, it becomes clear why Kitcher defends a pragmatist position: As altruism failures repeatedly occur throug- 
hout human history and the invention of new social rules and mechanisms of control never prevent all the potential for social conflict, there is no state to be reached in ethics, where evolution comes to an end. Every development of new social rules is at risk of either not correcting all altruism failures or creating new potential for social conflict. Hence, what can be reached in ethics are social rules which, at best, solve the social problems of a particular group at a certain time and place. In consequence, there is no objective yardstick by which to evaluate progress in ethics. This makes it difficult to talk about progressive changes in ethics being an accumulation of ethical truths.

In what follows, I will explain in more detail the underlying arguments Kitcher provides in his book to defend his theory. First, I introduce the naturalist preconditions which ground the ethical project (1.1). Thereafter I will discuss the relation between truth and progress in ethics (1.2). This discussion will explain why, I think Kitcher sees the role of ethics in human history being that of a mechanism for solving social conflicts and diminishing the risks of social instability.

\subsection{Human evolution and ethics}

According to Kitcher, the starting point of the ethical project lies in the fact that our pre-historical ancestors learned to live together in groups. Such ability must go hand in hand with a capacity to overcome selfish desires in order to serve the group: a capacity for psychological altruism $(\S 3)$. Both these presumptions of the starting point of the evolution of the ethical project are naturalist in kind, because they base ethics on the factual occurrence of these two evolutionary developments.

Although the assumption of an achieved ability for psychological altruism allows for cooperation to occur, this still cannot explain, why human beings are able to live in groups much larger than those of other hominids. Kitcher sees psychological altruism's lack of explanatory power on the matter of the expansion of human cooperation as sourced in the problem that the selfish disposition of human beings still encounters the risk of defection. Psychological 
altruism is limited. If no system of social control for such defection is installed, then an expansion of human cooperation is not feasible. Correcting for failures in altruistic behaviour can only be achieved by costly and inefficient battling among the members of a group $(\S 10)$.

Therefore, the expansion of human cooperation can only be explained by either the development of a more extensive capacity for psychological altruism or further capacities. Kitcher argues for both, although he puts more weight on the development of the further capacities. Included among these is as crucial achievement, a capacity for normative guidance. Normative guidance is the human capacity to reinforce altruistic demands by following social rules. Our ancestors learned, in the most primitive way, to follow commands enforced by their fellow cooperators through punishment $(\S \S 11,12)$. During human evolution such enforcement was increasingly internalized: First, social rules were enforced through direct (physical) punishment, then those rules were understood as being enforced by divine or other unseen powers. Later normative guidance developed into a psychological disposition for self-control ( $\S 13)$.

Kitcher sees this achievement as an important factor in evolution, explaining how our hominid ancestors became human. Additionally, this shows why humans were able to live in much larger groups than other hominids: Combined with the ability of language, they were able to fix altruism failures much more efficiently and were able to reinforce social rules, through the establishment of ethical codes ( $\S 14)$. However, different human groups established different ethical codes which best served to diminish altruism failures and disobedience of their own particular normative commands. Hence, Kitcher's account of the evolution of ethics leads to ethical pluralism (§ 16).

According to Kitcher, part of this process can be explained by the development of the two capacities grounding the ethical project: psychological altruism and normative guidance. Development of psychological altruism means the expansion of a psychological disposition to recognise other's desires as action guiding. More 
important in this process, however, is the development of the capacity for normative guidance because it allows to correct more efficiently for altruism failures and to ensure social stability. Therefore, change in the ethical project is possible insofar as human beings are able to develop their two basic capacities ( $\S \S 15-21)$. Interestingly, Kitcher makes a further proposal: It is not only the development of these capacities which provoked changes in ethical codes, but also the developments in ethics which had and have impact on the expansion of these two capacities. Hence, as Kitcher sees it, the evolution of ethics influences the capacities on which the project is itself grounded $(\S 23)$. On my view, taken together, these correlative developments give a persuasive framework for explaining why human beings were able to develop the way they did.

\subsection{Truth and Progress}

According to Kitcher, ethical codes must be understood as historical developments of human groups which had to solve specific altruism failures and risks of social instability $(\S 1)$. Hence, changes in ethics can only be judged as serving best the purposes of human groups at a particular time and place. Therefore, evolution in ethics leads to the invention of ethical codes and social rules, which might or might not display ethical progress $(\S \S 28,32)$ : This makes ethics out to be a never-ending story, because future human beings will always have further needs to be fulfilled, which require as yet undecided ethical codes. Additionally, this means that evolution in ethics cannot be understood as a permanent progressive development during which ethical truths are discovered $(\S 38) .^{2}$

A serious problem follows from this line of reasoning. One can

${ }^{2}$ This might seem absurd, because it means that the same would apply to science. However, according to Kitcher, at least some human practices follow the same kind of developmental processes $(\S \S$ 1, 34): In technology, invention means solving a functional problem once posed. Functional refinement of a once invented solution for such a problem means progress only insofar as it generates better 
either think that no standard for progress in the ethical project can be defined since changes in ethics take place as contingent occurrences, or one can object that progress in ethics necessarily means the accumulation of ethical truths $(\S \S 22,29,30)$. The first option is problematic because it provides no instrument to criticize barbarous ethical practices. If ethical practices occur as contingent facts, then a return to slavery or a Nazi regime has to be accepted as a mere change, which allows certain social groups to fix, in an efficient manner, altruism failures and the disobedience of social rules at a certain time and place. The second challenge is blocked because it would put into question Kitcher's whole theory so far.

To escape this dilemma, Kitcher proposes that ethical progress be prior to ethical truth $(\S 32)$. As shown before, according to the naturalist basis of the ethical project, progress can occur in two ways. Progress takes place, in one way, when the capacity for psychological altruism expands to a wider range of individuals. In addition, progress occurs when the capacity for normative guidance is refined. Both these processes lead to transitions in ethical codes, because altruism failures can be fixed more efficiently if they are linked with ethical codes allowing the reinforcement of respective altruistic behaviour and the obedience of social rules. As Kitcher believes that changes in ethical codes have had and continue to have an impact on the expansion of the two capacities grounding the ethical project, this shows why ethical codes are in permanent change. When a new ethical code is installed, it influences the two capacities. Insofar as these capacities expand then they provoke the development of another ethical code $(\S 33$.).

performance. Measuring such progress does not entail any reference to some notion of truth. Additionally, in "The Ethical Project", Kitcher mentions philosophical positions which ascribe the same to mathematics ( $\S \S 1,30,31)$. On my view, it would even be possible to understand Kitcher's pragmatist position with regard to science in the same way $(1985,2001$, and 2007). However, in this paper I cannot argue for this view. 
Such development must not be understood as the creation of expert members of a society. Kitcher sees ethical codes as an assemblage of functions which fix the risk of different altruism failures ( $\S \S 34-36)$. Hence, development of new ethical codes must be understood as an adaption by small steps when correcting for such failures. This does not entail special knowledge of the wider social conflicts and risks for social instability involved. It only demands an awareness of those altruism failures which have to be fixed. As a result, change in ethical codes takes place when new functions which fix altruism failures are installed. Those proposing them do not have to know if such changes lead to progressive transitions ( $(29)$.

Therefore, progress in ethics is not achieved in virtue of accumulating truths by experts. Rather, what counts as achieved truth in ethics can only be those parts of ethical codes, social rules or functions which survive an indefinite sequence of transitions in ethical codes. Those features of the ethical codes, social rules and functions which at some stage of human history enter ethics and remain as achievements within the project, are what becomes to be ethical truths. Therefore, it is not possible to talk of truths as objective yardstick to judge progress in ethics, but rather to talk about achievements which happen to be true in the course of the ethical project itself. These achievements allow later generations to judge which changes in ethical codes have to be evaluated as progress $(\S 38)$.

\section{Ethical codes as self-conception}

To my mind, put together, the naturalist and the pragmatist part of Kitcher's theory provide a very realistic and plausible explanation for why human development occurred the way it did. Realistic, because the two capacities - psychological altruism and normative guidance - grounding the ethical project, provide strong explanatory power and are persuasively backed by empirical research. Plausible, because discussing truth in ethics Kitcher pro- 
vides a cogent argument for why progress in ethics must not be understood as the accumulation of truths.

As convincing, as I take Kitcher's theory to be, however, I don't think it yet captures fully the role ethics plays in human history. Kitcher explains why human evolution was possible only in terms of the way it developed, but he delivers no explanation as to why particular developments and progressive changes took place. From Kitcher's perspective, such an explanation might neither be necessary nor possible, because such changes must be understood as net changes with regard to a complex bundle of functions that fixes altruism failure, together with further developments in human evolution. In contrast, I think if one enriches the role ethics plays in human history, the explanatory power of Kitcher's theory gets even stronger. Such enrichment can be provided if one understands ethical codes and social rules not only as a mechanism for fixing altruism failures and risks of social instability, but also as the invention of different self-conceptions.

In the next subsection I will explain, why I think Kitcher's framework motivates such an enrichment of the role ethics played in human history (2.1). Thereafter, I will show how the development of self-conceptions can explain at least certain changes in ethical codes and social rules (2.2). These proposals, however, are only working hypotheses.

\subsection{Conceptions of the good and self-conceptions}

Established ethical codes or social rules have an impact on the expansion of psychological altruism and the refinement of the capacity for normative guidance. According to Kitcher, both kinds of development go hand in hand with an expansion of the possibilities of leading worthwhile and rich lives (§ 36). Kitcher explains this expansion the following way: If the two capacities grounding the ethical project are developed and call for respective ethical codes, this has two consequences for the individuals involved. First, this development enables to expand the circle of those individuals counting as normatively relevant. Secondly, development of more complex ethical codes allows for more possibilities to establish 
various individual conceptions of the good. Such refinement of ethical codes, combined with a growing division of labor, calls for a wider range of social positions to be filled. Consequently, ethical progress allows for a wider range of life plans to be realized. This line of reasoning shows, why the formation of conceptions of the good and the respective expansion of possibilities to lead worthwhile and rich lives is a byproduct of evolution in ethics $(\S$ 20).

Indicative of this process is the following: Our earliest ancestors were mostly concerned with their survival. Their conception of the good must have been closely linked with getting enough food and ensuring protection from danger. By contrast, in ancient Greek cities we already find a complex division of labor involving a wide diversity of social positions, which need to be fulfilled. As inhabitants of ancient Greek cities were protected through several institutions from risk of starvation, their conception of the good must have changed accordingly: In these cities it became more important to develop one's talents to best serve the community. The new conception of the good - although it might have contained a connection to the need for survival - introduced the importance of developing one's talents as part of having a worthwhile and rich life $(\S \S 19,20)$.

Such formation of a new conception of the good can be explained by factors external to the ethical project and the simple fact that ethical codes change. In our example, the external factors are a need and ability for a division of labor. Internal to the project, Kitcher's theory only permits the ascertainment that a refined ethical code occurred. Admittedly, this cannot explain what processes in the evolution of ethics led to social conflict which called for correction. Hence, on my view, Kitcher's theory cannot explain what exact processes cause the development of specific new ethical codes and social rules.

Kitcher might argue that such an explanation is neither necessary nor possible because pragmatic naturalism only shows how evolution in ethics is possible and what future development ethical practice should take $(\S 2)$. However, I think if one can show what 
processes provoked changes in ethical codes then two things can be shown. First, it is possible to explain why changes in the evolution of ethics occurred the way they did and why certain changes were regressive rather than progressive. Secondly, one can give more detailed reasons for what direction future ethical practices should take. To see what exact processes provoke change in ethical codes, however, the role ethics plays in human history has to be enriched: The development of new ethical codes leads not only to new conceptions of the good, but also to changes in selfconceptions. ${ }^{3}$ Such changes can explain what processes provoke change in ethical codes.

Hence, I believe that development in ethics is not only due to a need for diminishing altruism failures and risks of social instability, but also due to changes in self-conceptions of individuals living under any ethical code. In consequence, on my view, any ethical code is always tied to a specific self-conception. As I will show in the next section, this permits detecting the processes which lead to changes in ethical codes.

\subsection{Progress and self-conceptions}

At some stage in human history our ancestors developed the capacity of oral, and later written, language. Kitcher sees these developments as providing important conditions which can explain why humans were able to form complex ethical codes to fix altruism failures, and also to efficiently divide labor for the fulfillment of their needs ( $\S 10)$. However, being capable of language not only allows debate over the efficient fulfillment and the realization of problematic tasks, it also allows asking questions. These questions were, among other things, concerned with difficulties in survival, with social conflicts, and with occurrence of certain unfairness and death. Answering these questions leads to the explanations given in myths, stories and religion, explaining why members of a group at a certain time and place live under the conditions they do and how they relate to their natural

$\overline{3}$ This argument is inspired by Roughley (2000: 27f. \& 45f.). 
and social environment (Wolf 1991: 115). Whilst for Kitcher such myths, stories and religion play a crucial role in the development and enforcement of ethical codes, I suggest that they also serve to answer such specific questions.

Human beings who are confronted with natural threats pose questions, just like members of more developed communities. Therefore, as social groups become more developed so those answers or stories have become more complex. Together with developments in science, it becomes evident that throughout human history answers to these questions have lost their mystical and religious character. As a result, I believe, ethical codes are nowadays less bound to divine regulation, but still serve the task of responding to the initial questions which came up when our ancestors started using language.

If survival is the core element of a conception of the good, then respective individuals understand themselves as vulnerable creatures at the mercy of dangerous nature. When the development of one's talents gets into focus of a conception of the good, then one's self-conception changes profoundly. Members of ancient Greek cities understood themselves as beings who have power over their development and who can choose which direction their lives might take. Paired with an ethical code which divides humans into masters and slaves, this leads to a conception of human beings where some are allowed to develop freely and others have to follow their master's command. Members of each of these two social classes have to develop their own self-conceptions explaining why they belong to their class and relate to the other the way they do. ${ }^{4}$ If this analysis is correct, then the development of self-conceptions at a certain time and place provides an explanation for the occurrence of change in the ethical project: At least some changes in ethical codes took place because the self-conception of at least some members of a group changed what provoked social conflict. If it was not change in self-conception that provoked social conflict

${ }^{4}$ Aristotle's Nicomachean Ethics might count as a theory to exactly explain these different self-conceptions and the respective relations between masters and slaves. 
but rather the problems of altruism failure, then such a change led itself to a new self-conception. Such a new self-conception then might have provoked further changes in ethical codes.

An informative example for a change, driven by a new selfconception, is the French revolution: Before the revolution it was clear that some French - the aristocrats - were controlling economic goods. This supposed entitlement was not justified by effort or economic action, but only by divine ancestry. However, as the bourgeois started to get more economic power, their self-conception, explaining their relation to the aristocrats, changed. They started seeing success as closely linked to effort, something which cannot be explained by divine ancestry. A new self-conception evolved among those people of France, which refused to accept differences imposed by divine ancestry. As such evolution of a new self-conception produced social conflict; a new ethical code had to be established to fix it.

It seems to me to be very plausible that change in the evolution of ethics can be - at least in some cases - explained by the occurrence of new self-conceptions. However, if one accepts this thesis and the earlier point that ethical codes are always tied to specific self-conceptions, a further conclusion has to be accepted. If Kitcher is correct, that those aspects of ethical codes, which, at some stage of human history, enter ethics and remain as achievements within the project, make manifest vague, core truths in ethics, then ethical codes must also make manifest what we are to understand by vague, core truths about human nature. This is because self-conceptions are conceptions of us; of what our nature includes. Furthermore, because the ethical project is a neverending story, those parts of self-conceptions, which happened to be true, show what future direction our ethical practice should take; it should establish or propose ethical codes and social rules which best capture those achieved vague, core truths. 


\section{Conclusion: how the two perspectives complement each other}

To summarize, Kitcher's perspective on the role of ethics in human history can be understood as a mechanism for problemsolving within social communities which, as a side effect, enriches the possibilities for living worthwhile and rich lives. From Kitcher's point of view, therefore, the ethical project is to be regarded as a cooperative venture which allowed diminishing social conflict and reducing the risks of social instability more and more efficiently.

In addition, I think that the ethical project not only fulfils this role, but provides human self-conceptions. These conceptions allowed and allow us human beings to understand why we live under the conditions we do and how we relate to our natural and social environment. Changes in these self-conceptions explain - at least in some cases - why social conflict occurred and new ethical codes have been established and provide reasons for what future direction our ethical practices should take. Therefore, while Kitcher tells one part of the story of evolution in ethics, I think he does not consider the wider role ethics plays in human history.

However, just what self-conceptions as part of human communities at specific times and places existed, can only be derived from the conceptions of the good which have evolved, and which are here worked out by Kitcher. Just as Kitcher's perspective informs the view of the ethical project I am proposing, I would hope my proposal might inform that of Kitcher's. Consequently, the proposed enriched role ethics plays in human history does not call into question Kitcher's point of view, but hopes to enhance the explanatory power his theory provides. 


\section{References}

Aristotle: Nicomachean Ethics. Oxford: Oxford University Press, 1980.

Kitcher, P.: The Nature of Mathematical Knowledge. Oxford: Oxford University Press, 1983.

- Science, Truth, and Democracy. Oxford: Oxford University Press, 2001.

- Does 'Race' have a future? In: Philosophy and Public Affairs, 35, p. 293-317, 2007.

- The Ethical Project. Cambridge, Mass.: Harvard University Press, 2011, in press.

Roughley, N.: Anthropologie und Moral. In: Endreß, M./ Roughley, N. (eds), Anthropologie und Moral. Philosophische und soziologische Perspektiven, p. 13-52, Würzburg: Königshausen \& Neumann, 2000.

Wolf, U.: Philosophie und die Frage nach dem guten Leben. In: Koppe, F. (ed.), Perspektiven der Kunstphilosophie, p. 102120, Frankfurt am Main: Suhrkamp, 1991.

Arbeits- und Forschungsstelle für Ethik

Universität Zürich

Zollikerstrasse 117

8008 Zürich, Schweiz

wallimann@philos.uzh.ch 